УДК 622.232

DOI 10.36910/6775-2313-5352-2020-16-18

Стасюк В.М., к.т.Н., Андрощук I.B., к.с.-г.н.

Луцький національний технічний університет

\title{
ВПЛИВ ОКРЕМИХ КОНСТРУКТИВНИХ ПАРАМЕТРІВ ПРИВОДУ ІЗ ПНЕВМОМЕХАНІЧНОЮ СИСТЕМОЮ ПОВІТРОРОЗПОДІЛУ НА РОБОЧІ ХАРАКТЕРИСТИКИ ВІБРОУДАРНИХ МАШИН
}

Завдання вибору оптимальних конструктивних параметрів приводів для забезпечення потрібних робочих характеристик віброударних пневматичних машин завжди актуальне, у тому числі й пневматичних приводів, системи повітророзподілу яких оснащені клапанними повітророзподільниками.

У статті наведені результати досліджень впливу окремих конструктивних параметрів приводу із пневмомеханічним розподілом стисненого повітря на робочі характеристики віброударних машин. В якості окремих конструктивних параметрів приводу вибрано: діаметри робочих вікон впускних елементів камер холостого та робочого ходів, діаметри випускних отворів $і$ відстань між осями впускних елементів камери холостого ходу та випускними отворами. При цьому для вибору більш досконалої конструкції приводу розглядалися три його конструкиії: із регульованим дроселем у кришиі компенсаційної камери холостого ходу, із регульованим дроселем у кришиі компенсаиійної камери робочого ходу та без регульованих дроселів у кришках вищезазначених камер. В якості робочих характеристик віброударної машини вибрані: енергія удару, частота ударів, хід поршня-ударника та тривалість ициклу.

Отримані результати досліджень дозволяють вибирати оптимальні величини конструктивних параметрів приводу із пневмомеханічною системою повітророзподілу для забезпечення потрібних робочих характеристик віброударної машини.

Ключові слова: пневмопривод, енергія удару, частота ударів, хід поршня-ударника, тривалість ииклу.

Постановка проблеми. Від правильності вибору конструктивних параметрів пневматичних приводів, зокрема, і з пневмомеханічним повітророзподілом, істотно залежить можливість досягнення заданих робочих характеристик віброударних машин, а також енергоємність їх робочих процесів. Тому дослідження пневматичних приводів на предмет визначення оптимальних величин їх конструктивних параметрів 3 метою забезпечення потрібних експлуатаційних показників при якомога менших енергозатратах (а енергія стисненого повітря досить дорога) $є$ актуальним науковим і прикладним завданням.

Аналіз останніх досліджень і публікацій. Окремі результати досліджень пневматичних приводів під вищезазначеним кутом наведені в роботі [1]. Однак приводи із пневмомеханічними системами повітророзподілу для віброударних машин у цій роботі не розглядаються.

Формулювання цілей статті. Дослідити вплив окремих конструктивних параметрів приводу із пневмомеханічним розподілом стисненого повітря на робочі характеристики віброударних машин.

Результати досліджень. У роботі наведені результати досліджень впливу окремих конструктивних параметрів приводу із пневмомеханічною системою повітророзподілу на робочі характеристики віброударних машин на його основі без проміжних розрахунків. В якості досліджуваних конструктивних параметрів приводу вибрано:

- діаметри робочих вікон впускних елементів камер холостого та робочого ходів (відповідно $d_{k 1}$ і $d_{k 2}$ );

- діаметри випускних отворів $\left(d_{6.0 .}\right)$;

- відстань між віссю клапана пневморозподільника камери холостого ходу та віссю випускних отворів $(l)$.

Досліджувався вплив зазначених конструктивних параметрів на такі основні робочі характеристики віброударних машин:

- енергія удару $\left(E_{y}\right)$;

- частота ударів $(f)$; 
- хід поршня-ударника $(s)$;

- тривалість циклу $\left(t_{u}\right)$.

На наведених нижче рисунках відображені основні результати досліджень. На них:

- $E_{y l}, f_{l}, s_{l}, t_{u l}$ - відповідно енергія удару, частота ударів, величина ходу поршня-ударника та тривалість циклу для приводу із регульованим дроселем у кришці компенсаційної камери холостого ходу;

- $E_{y 2}, f_{2}, s_{2}, t_{u 2}$ - відповідно енергія удару, частота ударів, величина ходу поршня-ударника та тривалість циклу для приводу без регульованих дроселів у кришках компенсаційних камер холостого і робочого ходів;

- $E_{y 3}, f_{3}, s_{3}, t_{u 3}$ - відповідно енергія удару, частота ударів, величина ходу поршня-ударника та тривалість циклу для приводу із регульованим дроселем у кришці компенсаційної камери робочого ходу.

Варіювання здійснювалось величиною одного (досліджуваного) конструктивного параметра, не змінюючи величини інших.

Залежності робочих характеристик віброударних машин від діаметрів робочих вікон впускних елементів камер холостого та робочого ходів (відповідно $d_{k l}$ i $d_{k 2}$ ) зображені на рис. 1 . При цьому під час досліджень величини $d_{k 1}$ i $d_{k 2}$ приймались однаковими, визначеними за формулою:

$$
d_{k 1}=d_{k 2}=\sqrt{\frac{4 f_{\text {np.nep. }}}{\pi}}-d_{U},
$$

де $f_{\text {nр.пер. }}$ - площа прохідного перерізу робочих вікон впускних елементів системи повітророзподілу, однакова в обох пневморозподільниках; $d_{u}$ - діаметр штока, однаковий в обох клапанах пневморозподільників.

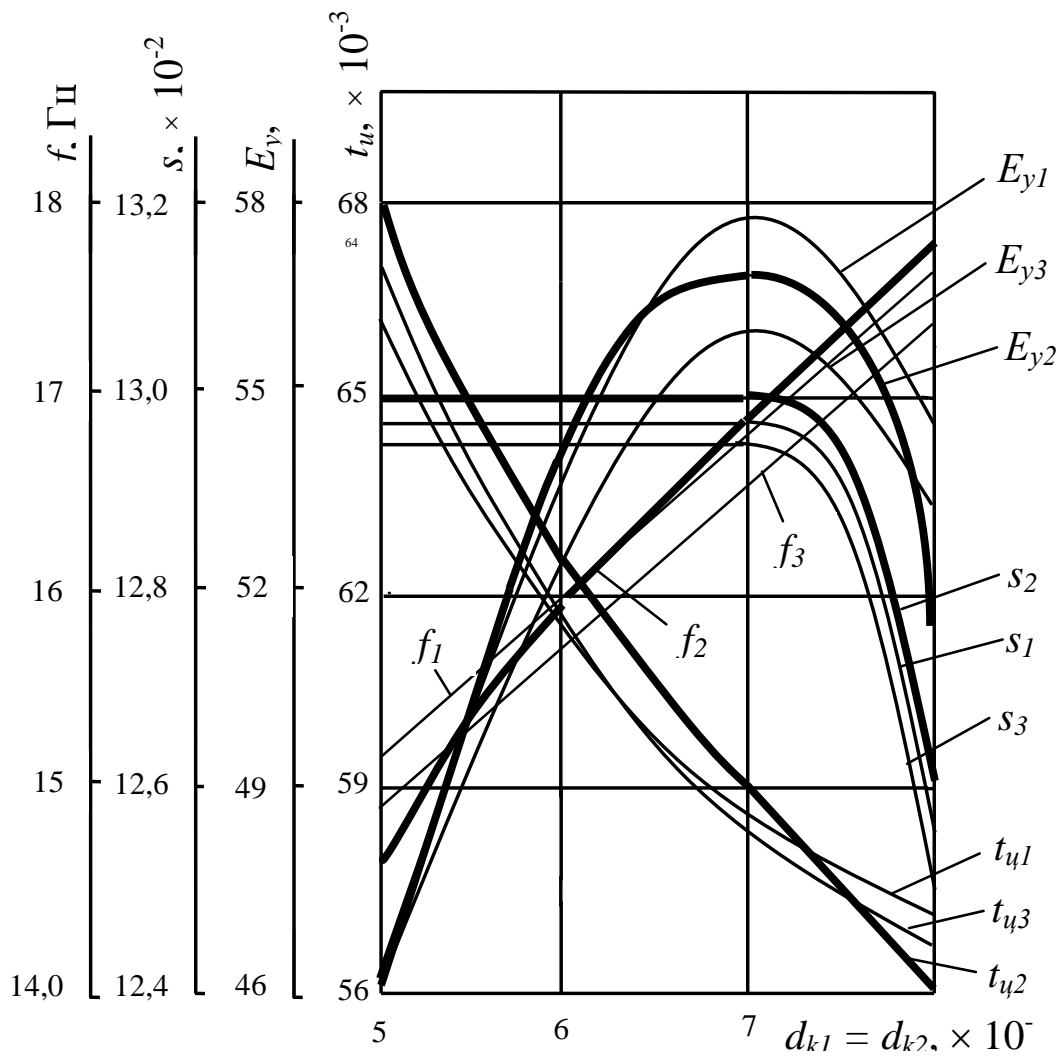

Рис. 1. Залежності робочих характеристик віброударних машин від величин діаметрів робочих вікон $d_{k l}$ і $d_{k 2}$ впускних елементів системи розподілу стисненого повітря пневматичного приводу $\left(l=85 \times 10^{-3} \mathrm{M} ; d_{\text {в.o. }}=5 \times 10^{-3} \mathrm{M}\right)$

Аналіз наведених графіків показує, що оснащення компенсаційної камери холостого ходу регульованим дроселем дозволяє досягнути збільшення енергії удару майже до 58 Дж при 
величині діаметрів робочих вікон $d_{k l}$ i $d_{k 2}$ впускних елементів системи повітророзподілу, рівних $7 \times 10^{-3} \mathrm{M}$.

Отримання найвищої частоти ударів (до 18 Гц) забезпечує пневматичний привод, компенсаційні камери холостого та робочого ходів якого не оснащені регульованими дроселями. При цьому діаметри робочих вікон $d_{k 1} \mathrm{i} d_{k 2}$ впускних елементів системи повітророзподілу повинні становити $8 \times 10^{-3} \mathrm{M}$.

Результати проведених досліджень свідчать, що хід поршня-ударника практично не залежить від величини діаметрів робочих вікон $d_{k 1} \mathrm{i} d_{k 2}$ впускних елементів системи повітророзподілу, і тільки коли вони перевищують $7 \times 10^{-3}$ м, величина ходу починає інтенсивно зменшуватись.

Щодо тривалості циклу, то іiі найменші значення властиві для пневматичних приводів, компенсаційні камери холостого та робочого ходів яких не оснащені регульованими дроселями, при цьому при значеннях: $d_{k l}=d_{k 2}=8 \times 10^{-3}$ м.

Залежності робочих характеристик віброударних машин від діаметра випускних отворів $\left(d_{\text {в.o. }}\right)$ у стінках пневмоциліндра приводу зображені на рис. 2.

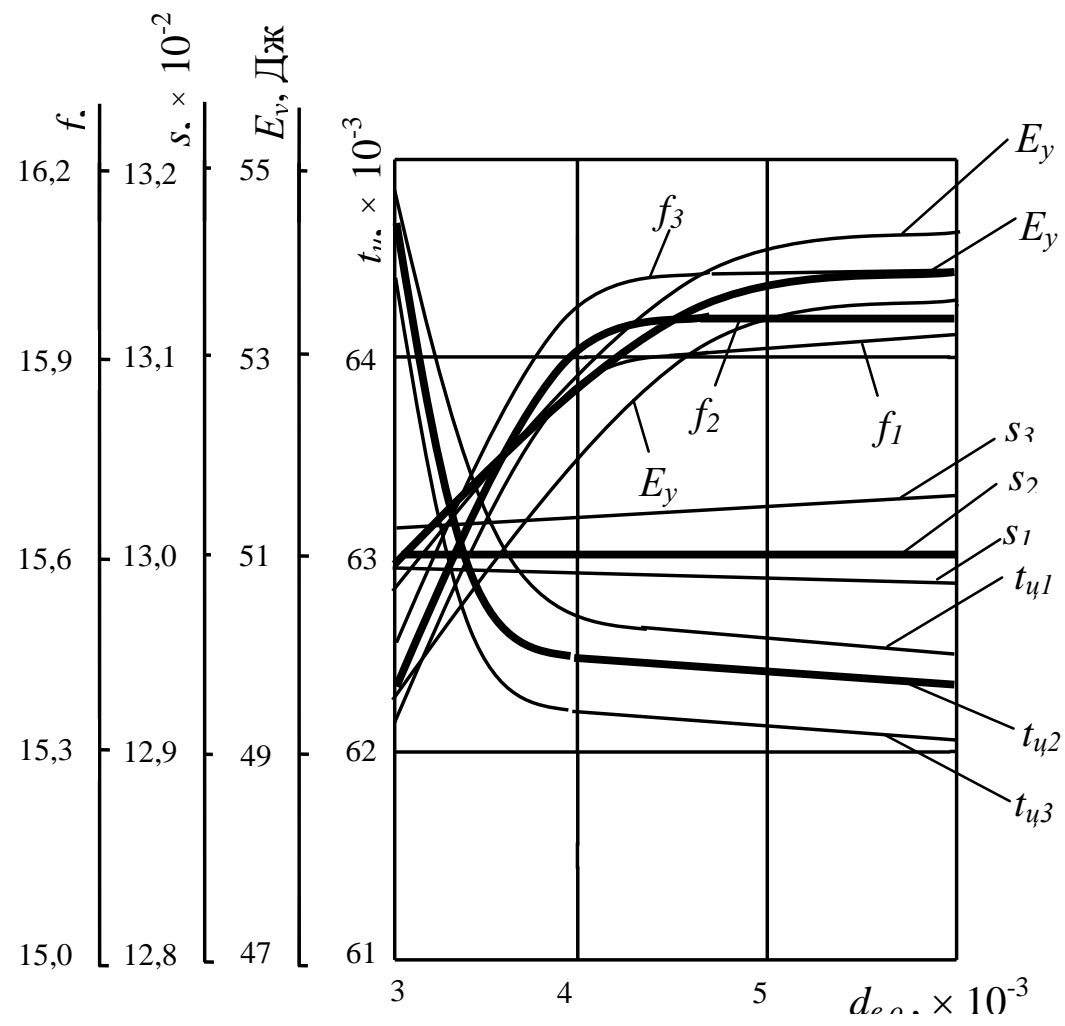

Рис. 2. Залежності робочих характеристик віброударних машин від діаметра випускних отворів $d_{6.0}$ у у стінках циліндра приводу із пневмомеханічною системою розподілу стисненого повітря $\left(l=85 \times 10^{-3} \mathrm{M} ; d_{k l}=d_{k 2}=6 \times 10^{-3} \mathrm{M}\right)$

Аналіз наведених залежностей свідчить, що найвищої величини енергії удару (до 54 Дж) можна досягнути у випадку оснащення компенсаційної камери холостого ходу регульованим дроселем при $d_{6.0 .}=6 \times 10^{-3} \mathrm{M}$.

Найвища частота ударів поршня-ударника властива для приводів, кришки компенсаційних камер робочого ходу яких оснащені регульованими дроселями - величина $f_{3}$ у них перевищує 16 Гц.

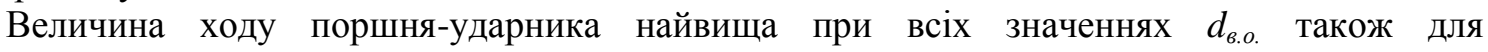
пневматичних приводів, в яких одним із конструктивних елементів $\epsilon$ регульований пневмодросель камери робочого ходу.

Тривалість циклу найменша для величини діаметра випускних отворів $d_{\text {в.o. }}=6 \times 10^{-3} \mathrm{M}$ також для вищезазначених пневмоприводів. 
Залежності робочих характеристик віброударних машин від відстані між осями впускних елементів камери холостого ходу та випускними отворами $(l)$ зображені на рис. 3 . Їх аналіз показує, що:

- найбільша енергія удару забезпечується у випадку відсутності в кришках компенсаційних камер робочого та холостого ходів регульованих дроселів - iї значення сягає 54 Дж;

- найвище значення частоти ударів у всьому діапазоні значень відстані між осями впускних елементів камери холостого ходу та випускними отворами $l$ властиве для пневматичних приводів, компенсаційні камери холостого ходу яких оснащені регульованими дроселями;

- найменша тривалість робочого циклу властива для всього діапазону значень відстані $l$ також для пневмоприводів із регульованими дроселями у компенсаційних камерах холостого ходу;

- найдовший хід у приводів без регульованих пневмодроселів, при цьому у інтервалі значень відстані між осями впускних елементів камери холостого ходу та випускними отворами від $85,0 \times 10^{-3}$ м до $88,6 \times 10^{-3}$ м.

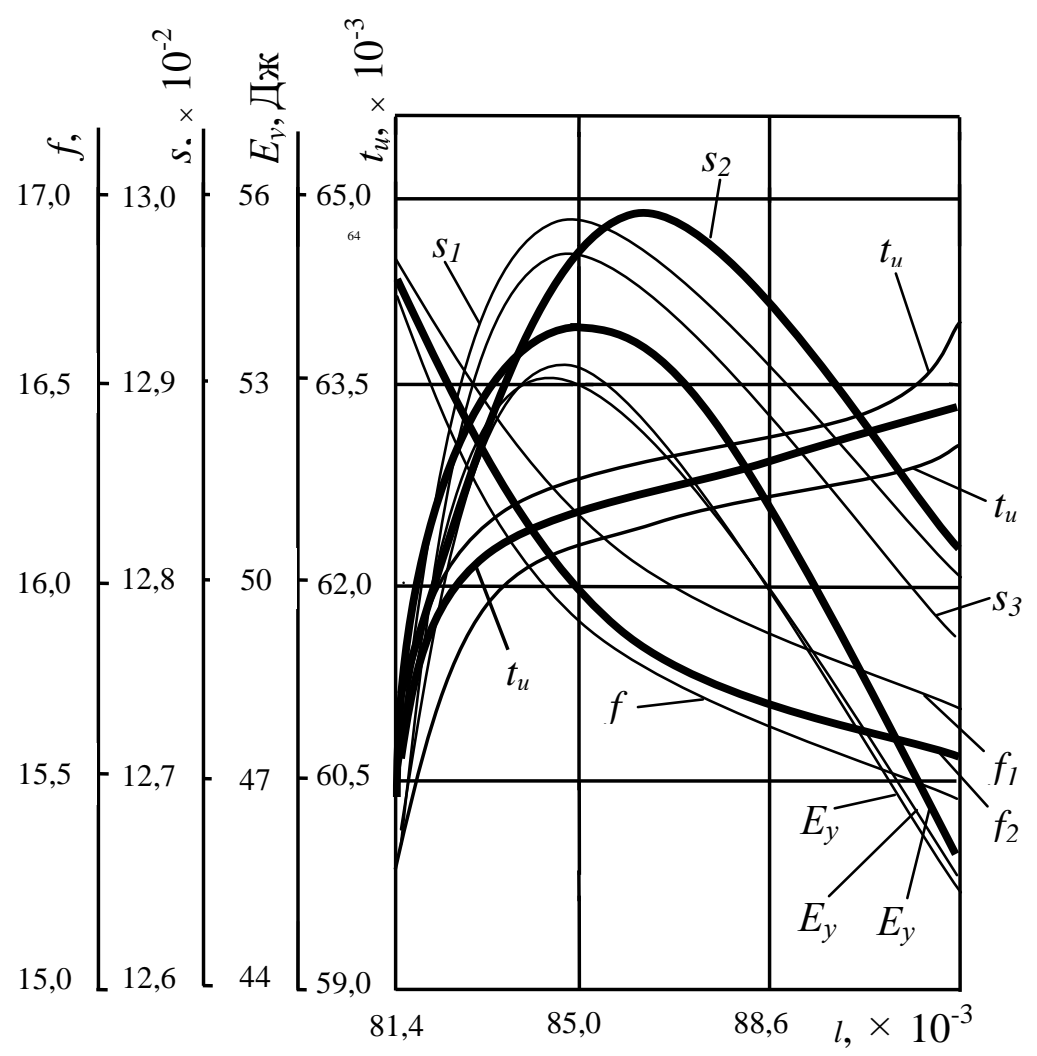

Рис. 3. Залежності робочих характеристик віброударних машин від величини відстані між осями впускних елементів камери холостого ходу та випускними отворами $l$ циліндра пневматичного приводу $\left(d_{k 1}=d_{k 2}=6 \times 10^{-3} \mathrm{M} ; d_{\text {,.o. }}=5 \times 10^{-3} \mathrm{M}\right)$

Висновок. Отримані залежності дозволяють вибрати оптимальні значення конструктивних параметрів приводів із пневмомеханічними системами повітророзподілу для забезпечення потрібних величин робочих характеристик віброударних машин на їх основі під час проектних робіт.

\section{Інформаційні джерела}

1. Кузнецов К.А. Разработка и исследование регулируемого поршневого вибровозбудителя с пневмоприводом для строительных технологий: Дис...канд. техн. наук: 05.02.03. - Винница, 1998. -275 c. 
Стасюк В.М., к.т.Н., Андрощук И.В., к.с.-Х.н.

Луцкий национальный технический университет

\section{ВЛИЯНИЕ ОТДЕЛЬНЫХ КОНСТРУКТИВНЫХ ПАРАМЕТРОВ ПРИВОДА С ПНЕВМОМЕХАНИЧЕСКИЕ СИСТЕМОЙ ВОЗДУХОРАСПРЕДЕЛЕНИЯ НА РАБОЧИЕ ХАРАКТЕРИСТИКИ ВИБРОУДАРНЫХ МАШИН}

Задание выбора оптимальных конструктивных параметров приводов для обеспечения нужных рабочих характеристик виброударных пневматических машин всегда актуально, в том числе и пневматических приводов, системы воздухораспределения которых оснащены клапанными воздухораспределителями.

В статье наводятся результаты исследований влияния отдельных конструктивных параметров привода с пневмомеханическим распределением сжатого воздуха на рабочие характеристики виброударных машин. В качестве отдельных конструктивных параметров привода выбраны: диаметры рабочих окон впускных элементов камер холостого и рабочего ходов, диаметры выпускных отверстий и расстояние между осями впускных элементов камеры холостого хода и выпускными отверстиями. При этом для выбора более совершенной конструкции привода рассматривались три его конструкции: с регулируемым дросселем в крышке компенсационной камеры холостого хода, с регулируемым дросселем в крышке компенсационной камеры рабочего хода и без регулируемых дросселей в крышках вышеупомянутых камер. В качестве рабочих характеристик виброударной машины выбраны: энергия удара, частота ударов, ход поршня-ударника и продолжительность цикла.

Полученные результаты исследований позволяют выбирать оптимальные величины конструктивных параметров привода с пневмомеханической системой воздухораспределения для обеспечения требуемых рабочих характеристик виброударной машины.

Ключевые слова: пневмопривод, энергия удара, частота ударов, ход поршня-ударника, продолжительность цикла.

Stasiuk V.M., Androschuk I.V.

Lutsk National Technical University

\section{INFLUENCE OF SOME CONSTRUCTIVE PARAMETERS OF DRIVE WITH PNEUMO- MECHANIC SYSTEM OF AIR DISTRIBUTION ON WORKINGS CHARACTERISTICS OF VIBRO-PERCUSSION MACHINES}

The choice of optimum constructive parameters of drives for providing of necessary workings characteristics of vibro-percussion pneumatic machines has always been actual, including pneumatic drives, air distribution systems of which are equipped with valvular air distributors.

The article presents the researches results of influence of some constructive parameters of the drive with the pneumo-mechanic distributing of compressed air on the workings characteristics of vibro-percussion machines. Some constructive parameters of the drive are determined: diameters of workings windows of the inlet elements of chambers of no-load and working motions, diameters of inlets and distance between the axes of the inlet elements of chamber of no-load and inlets. Thus for the choice of more perfect construction of the drive three constructions were examined: with the managed throttle in the lid of compensative chamber of no-load, with the managed throttle in the lid of compensative chamber of working motion and without the managed throttles in the lids of aforementioned chambers. Energy of blow, frequency of percussion, motion of piston-shock-worker and duration of cycle are chosen as the main workings characteristics of vibro-percussion machine.

The researches results allow to choose the optimum sizes of constructive parameters of the drive with the pneumo-mechanic system of air distribution for providing of necessary workings characteristics of vibro-percussion machine.

Keywords: pnevmo-drive, energy of percussion, frequency of percussion, motion of pistonshock-worker, duration of cycle. 